\title{
Seeds of change: Establishing frameworks for understanding global environmental changes
}

\author{
This article belongs to Ambio's 50th Anniversary Collection. Theme: Agricultural land use
}

\author{
Angelina Sanderson Bellamy
}

Published online: 13 March 2021

Agriculture is the single most significant driver of land use change across the globe. Approximately half of the world's habitable land area has been converted to agricultural production (Ellis et al. 2010), which is a significant cause of biodiversity loss and greenhouse gas emissions. The global community has recognised the urgency by which we must reverse biodiversity loss and halt greenhouse gas emissions. While international will to reverse biodiversity loss and land degradation exists, as evidenced by the 1992 Convention on Biological Diversity and subsequent Aichi Biodiversity targets agreed in 2010, action to do so has failed. The most recent UN Global Biodiversity Outlook 5 report ${ }^{1}$ found that despite progress in some areas, natural habitats have continued to disappear, vast numbers of species remain threatened by extinction from human activities, and $€ 314$ billion of environmentally damaging government subsidies have not been eliminated. Government action and investment to support commitments to reverse land degradation and support biodiversity must be implemented to realize the vision agreed by world governments for 2050, to live in harmony with nature.

The Paris Agreement, which entered into force in November 2016 has as its central aim to strengthen the global response to the threat of climate change by keeping a global temperature rise this century well below $2{ }^{\circ} \mathrm{C}$ above pre-industrial levels and to pursue efforts to limit the temperature increase even further to $1.5^{\circ} \mathrm{C}$. This has been equated to achieving zero net emissions by 2050 . This represents a significant shift compared to the rather openended and bland target from the Kyoto Protocol of 1997 to reduce the atmospheric concentration of greenhouse gases to "a level that would prevent dangerous anthropogenic interference with the climate system" (Article 2). The long-standing debates then were between negotiators about the role that industrialised countries should play compared to those countries still developing their economies in the lead up to and after the Kyoto Protocol. However, reaching net zero emissions by 2050 will require significant changes in the business as usual scenario.

Achieving both the Paris Agreement and the Aichi Biodiversity targets will require a transformation of the way we currently use land and produce food. It will not be possible to reach either target without addressing land use and agricultural production. Nature-friendly approaches to farming, such as agroecology, create possibilities of creating multi-functional landscapes which can provide food, land for biodiversity, AND carbon sequestration through both the soil and agroforestry.

The 1990s saw global leaders come together to agree the significance of climate change and biodiversity loss and this is the backdrop for the publication of the three articles that make up this anniversary collection: (Sombroek et al. 1993; Turner et al. 1994; Brussaard et al. 1997). While the scientific community was galvanised behind these global challenges, as De Bremond (2021) outlines in her Perspective, it was still early days in understanding the critical role that agricultural land use changes had to play. Moore's Perspective (2021), recognises the role these articles played in establishing important frameworks for understanding global dynamics of land use changes. The authors themselves have also reflected on the impact of their earlier publications and the challenges of the time (Brussaard 2021; Nachtergaele 2021; and Turner et al. 2021).

The Ambio article by Turner et al. (1994) called for better "global-level data on land use and land-cover change...(and)...better understanding of the underlying driving forces for these changes." (p. 91). It recognised the

\footnotetext{
${ }^{1}$ https://www.unenvironment.org/resources/report/global-biodiversity -outlook-5-gbo-5.
} 
challenge of creating a generalised global model based on accumulated place-based case study data; indeed in the 25 years since publication, this objective has eluded the land system science research community, illustrating the complexity of social-ecological systems and the challenges that remain for achieving sustainable outcomes. In seeking to merge the social drivers with ecological system feedbacks to better understand and predict land use and land cover changes based on different policy and other social parameters, land system science gets to the core of Ambio's themes.

The Ambio article by Brussard et al. in 1997 was another example of the foreshadowing of years of work within a growing network of scientists, this time focused on soil biodiversity, whose aim was to better understand environmental changes and how these impact people. Like the Ambio article by Turner and colleagues, it highlighted the gaps in knowledge within the research community and was agenda-setting, culminating in a rigorous synthesis by Wall (2004) of the role of biodiversity both within and across soils and sediments in providing ecosystem services seven years later.

This brings us to the final article of this Ambio anniversary collection by Sombroek et al. (1993), which focused on another component of the soil system critical in our efforts today to reach zero carbon emission targets: carbon sequestration. Sombroek and co-authors brought attention to the need for understanding the human-environment interactions as they relate to land use practices and the possibility of carbon storage in below-ground biomass. All of the chosen articles advocated for a framework to understand the global environmental changes precipitated by human actions and the impacts of these changes on human population. They have culminated in research programmes pivotal for providing the building blocks on which our current understanding of the role that agricultural land use plays in predicating climate change and biodiversity loss. Results from these research programmes support our understanding for effecting positive change to achieve international targets for biodiversity and net zero greenhouse gas emissions.

\section{REFERENCES}

Brussaard, L. 2021. Biodiversity and ecosystem functioning in soil: The dark side of nature and the bright side of life. 50th Anniversary Collection: Agricultural Land Use. Ambio Volume 50. https://doi.org/10.1007/s13280-021-01507-z.

Brussaard, L., V.M. Behan-Pelletier, D.E. Bignell, V.K. Brown, W. Didden, P. Folgarait, C. Fragoso, D.W. Freckman, et al. 1997. Biodiversity and ecosystem functioning in soil. Ambio 26: 563-570.

De Bremond, A.C. 2021. The emergence of land systems as the nexus for sustainability transformations. 50th Anniversary Collection: Agricultural Land Use. Ambio Volume 50. https://doi.org/10. 1007/s13280-021-01519-9.

Ellis, E.C., K. Goldewijk, S. Siebert, D. Lightman, and N. Ramankutty. 2010. Anthropogenic transformation of the biomes, 1700 to 2000. Global Ecology and Biogeography 19: 589-606.

Moore, J.C. 2021. The re-imagining of a framework for agricultural land use: A pathway for integrating agricultural practices into ecosystem services, planetary boundaries and sustainable development goals. 50th Anniversary Collection: Agricultural Land Use. Ambio Volume 50. https://doi.org/10.1007/s13280-02001483-w.

Nachtergaele, F. 2021. Amounts, dynamics and sequestering of carbon in tropical and subtropical soils: A memory. 50th Anniversary Collection: Agricultural Land Use. Ambio Volume 50. https://doi.org/10.1007/s13280-021-01508-y.

Sombroek, W.G., F.O. Nachtergaele, and A. Hebel. 1993. Amounts, dynamics and sequestering of carbon in tropical and subtropical soils. Ambio 22: 417-426.

Turner, B.L., II., W.B. Meyer, and D.L. Skole. 1994. Global landuse/land-cover change: towards an integrated study. Ambio 23: 91-95.

Turner, B.L. II, E.F. Lambin, and P.H. Verburg. 2021. From landuse/land-cover to land system science. 50th Anniversary Collection: Agricultural land use. Ambio Volume 50. https://doi.org/ 10.1007/s13280-021-01510-4.

Wall DH (ed.), 2004. Sustaining Biodiversity and Ecosystem Services in Soils and Sediments. SCOPR report 64. Island Press, Washington D.C. https://islandpress.org/books/sustainingbiodiversity-and-ecosystem-services-soils-and-sediments.

Publisher's Note Springer Nature remains neutral with regard to jurisdictional claims in published maps and institutional affiliations.

Angelina Sanderson Bellamy ( $\square)$

Address: Sustainable Places Research Institute, Cardiff University, 33

Park Place, Cardiff CF10 3BA, UK.

e-mail: BellamyA1@cardiff.ac.uk 


\section{Amounts, Dynamics and Sequestering of Carbon in Tropical and Subtropical Soils}

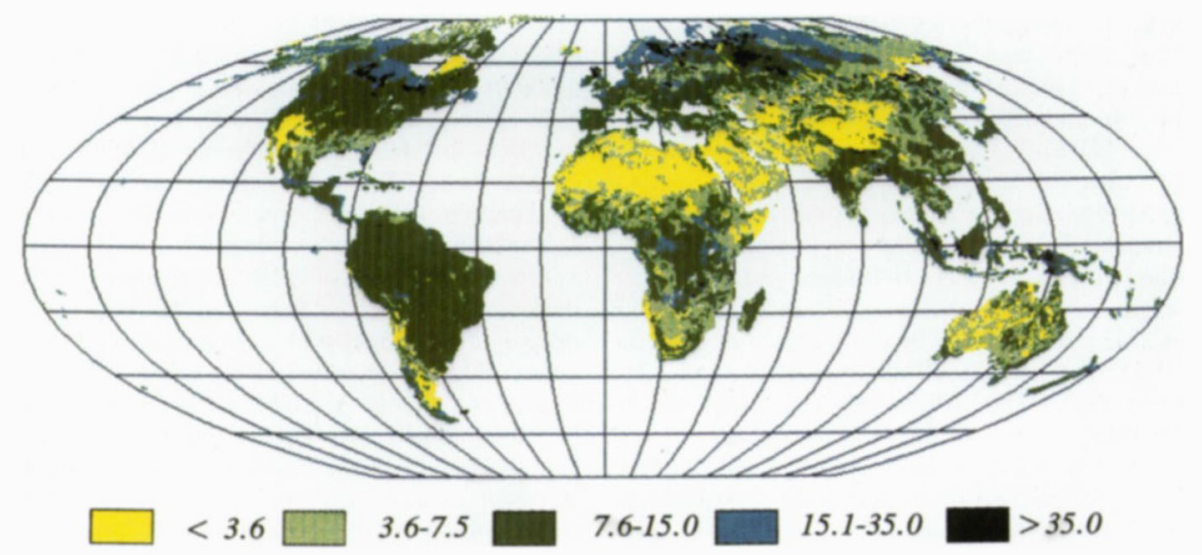

Figure 1. Soil organic carbon pool $\ln \mathrm{kg} \mathrm{C}^{-2}$ up to $1 \mathrm{~m}$ depth.

\begin{abstract}
The organic carbon pool in the upper $1 \mathrm{~m}$ of the world's soils contains $1220 \mathrm{Gt}$ organic carbon, 1.5 times the total for the standing biomass. In the widespread deep soils in the tropics the carbon stored below $1 \mathrm{~m}$ may add about $50 \mathrm{GtC}$. The contributions of charcoal, roots and soil fauna should be added to these totals. The much less dynamic carbonatecarbon pool amounts to $720 \mathrm{Gt} \mathrm{C}$. Changes in land use, particularly by clearing of forests, reduce organic carbon by 20 to $50 \%$ in the upper soil layers, but little in deeper layers. On the other hand, there are indications that a humaninduced enrichment of soil organic matter can be maintained over centuries. Research on the causative soil processes should be supported, because an improved understanding of this phenomenon might lead to better management strategies and sound programs to stimulate organic carbon storage and fertility levels in tropical and subtropical soils. Recent research data on the $\mathrm{CO}_{2}$ fertilization effect and the associated antitranspiration effect due to an increase of $\mathrm{CO}_{2}$ in the atmosphere indicate that a positive influence on soil organic carbon levels can be expected.
\end{abstract}

\section{INTRODUCTION}

Soil carbon is an important part of the terrestrial carbon pool. Its size has been estimated between 700 and $3000 \mathrm{Gt} C(1 \mathrm{Gt}=$ $10^{15} \mathrm{~g} \mathrm{C}$ ) as organic carbon and 780 to $930 \mathrm{Gt} \mathrm{C}$ as calcium carbonate. Other carbon pools are the oceans $(38000 \mathrm{GtC})$, fossil carbon reserves $(6000 \mathrm{Gt} \mathrm{C}), \mathrm{CO}_{2}$ in the atmosphere $(720 \mathrm{Gt} \mathrm{C})$, and biomass of plants $(560$ to $835 \mathrm{Gt} \mathrm{C})(1)$.

The beneficial effects for agricultural production of soil carbon in its organic form (fresh organic matter, humus) are wellknown: source of nutrients gradually becoming available to plants; increased aggregate stability; increased moisture storage capacity and increased microbial diversity and activity. Higher percentages generally improve the chemical, physical and biological status of the soil. In spite of this, sound organic-matter management practices remain the exception rather than the rule, particularly in tropical and subtropical environments. More recently, soil organic matter has received attention in scientific circles for its role in the sequestration of the greenhouse gas $\mathrm{CO}_{2}$, and the emission of $\mathrm{CO}_{2}, \mathrm{CH}_{4}$ and $\mathrm{N}_{2} \mathrm{O}$.

The objectives of this article are to refine current estimates of the organic soil carbon pools by using the recently corrected and digitized FAO/Unesco Soil Map of the World (2), to emphasize the role of sound organic-matter management, to explore the possibilities for soil-carbon sequestering, and to draw attention to possible effects of global climatic change on the soil-carbon pool.

\section{CARBON POOLS IN THE WORLD}

Average Soil Carbon Contents Based on the FAO/Unesco Soil Map of the World

\section{Organic Carbon}

Estimates of the storage of organic carbon in soils on a global scale vary between 700 and $3000 \mathrm{GtC}(1,3-11)$. This large variation is explained by the difference in base maps selected (FAO/Unesco Soil Map of The World, Holdridge Life Zones, Vegetation Maps) and the various assumptions made about soil attributes directly related to the total content of organic-matter per soil type such as organic matter content and distribution in the soil profile, bulk density of soil layers, and average soil depths.

In the present approach, the corrected and digitized FAO/ 


\section{Global Land-Use/Land-Cover Change: Towards an Integrated Study}

\begin{abstract}
Human actions are altering the terrestrial environment at unprecedented rates, magnitudes, and spatial scales. Landcover change stemming from human land uses represents a major source and a major element of global environmental change. Not only are the global-level data on landuse and land-cover change relatively poor, but we need a much better understanding of the underlying driving forces for these changes. Many forces have been proposed as significant, but single-factor explanations of land transformation have proved to be inadequate. How the human causes interact, and under what circumstances each is important, are questions needing systematic research. An international and interdisciplinary agenda is currently being developed to address these issues, through several closelyconnected foci of study. A division of the world according to common situations of environment, human driving forces, and land-cover dynamics will be followed by detailed study of the processes at work within each situation. The results will form the basis for a concurrent effort to develop a global land model that can offer projections of patterns of land transformation.
\end{abstract}

\section{INTRODUCTION}

Scientists and the public alike now understand that contemporary change in many realms of the biosphere is largely the product of human activities. Human impacts on the global environment are operating at unprecedented magnitudes, rates, and spatial scales. For example: at least half of the ice-free surface of the Earth has already been substantially altered for a variety of human uses (1); the annual human diversion of water is about a quarter of the total yearly stable runoff on all of the world's lands, and the amount either diverted or polluted is more than a third (2). In addition, the methane content of the troposphere has been doubled, and the level of carbon dioxide increased by $25 \%$, since preindustrial times (3).

The immediate human sources of these changes lie in two clusters of production and consumption activities (4). The first is the world's industrial metabolism; the flow of energy and materials through the processes of resource extraction, processing, use, and disposal in the industrial sector of the world economy (5). The second is global land-use and land-cover change. The division is a pragmatic one designed to make the field of study - the human sources of global environmental change-more manageable. No sharp division exists between the environmental effects that each cluster produces. Their impacts span a wide range of spatial scales and overlap in many areas. Industrial metabolism and land-use and land-cover change both contribute to such globally systemic changes as greenhouse-gas accumulation in the troposphere, and stratospheric ozone depletion. Over the past 150 years, for example, land-cover changes and fossil-fuel combustion have released approximately equal amounts of carbon dioxide to the atmosphere (6). Other impacts of both industrial metabolism and landuse and land-cover change are localized in their immediate reach

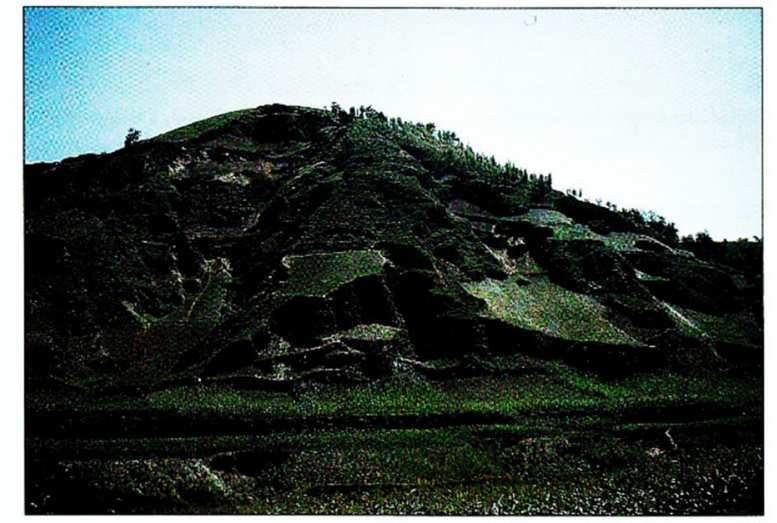

Wind and water erosion following forest clearance in loess area near Yan'an, Shaanxi Province, China. Photo: B. L. Turner II.

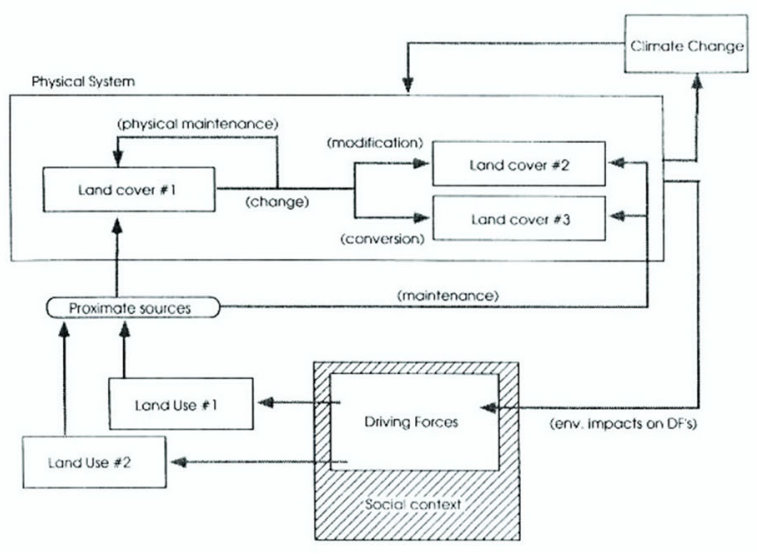

Figure 1. Linkages between human driving forces,

land use and land cover.

and become globally significant, if they do at all, only by widespread cumulative occurrence.

\section{LAND-USE/LAND-COVER RELATIONSHIP}

The most spatially and/or economically important human uses of land globally include cultivation in various forms, livestock grazing, settlement and construction, reserves and protected lands, and timber extraction. These and other land uses have cumulatively transformed land cover at a global scale. The consequences have been significant not only for land cover but for many aspects of local, regional, and global environments, including climate, atmospheric composition, biodiversity, soil condition, and water and sediment flows. These kinds of impacts are generated by both 
Article Lijbert Brussaard et al.

\section{Biodiversity and Ecosystem Functioning in Soil}

We review the current knowledge on biodiversity in soils, its role in ecosystem processes, its importance for human purposes, and its resilience against stress and disturbance. The number of existing species is vastly higher than the number described, even in the macroscopically visible taxa, and biogeographical syntheses are largely lacking. A major effort in taxonomy and the training of a new generation of systematists is imperative. This effort has to be focussed on the groups of soil organisms that, to the best of our knowledge, play key roles in ecosystem functioning. To identify such groups, spheres of influence (SOI) of soil biota-such as the root biota, the shredders of organic matter and the soil bioturbators-are recognized that presumably control ecosystem processes, for example, through interactions with plants. Within those $\mathrm{SOI}$, functional groups of soil organisms are recognized. Research questions of the highest urgency are the assignment of species to functional groups and determining the redundancy of species within functional groups. These priorities follow from the need to address the extent of any loss of functioning in soils, associated with intensive agriculture, forest disturbance, pollution of the environment, and global environmental change. The soil biota considered at present to be most at risk are species-poor functional groups among macrofaunal shredders of organic matter, bioturbators of soil, specialized bacteria like nitrifiers and nitrogen fixers, and fungiforming mycorrhizas. An experimental approach in addressing these research priorities is needed, using longterm and large-scale field experiments and modern methods of geostatistics and geographic information systems.

\section{INTRODUCTION}

Much of the terrestrial biosphere resides in the soil, largely unnoticed by professional biologists and lay people. This is ironic because the soil provides the physical substratum for virtually all human activities, e.g., agriculture, buildings, transport; it provides resources for industrial use and waste management; and it is central in elemental cycles, without which agriculture would not be possible. Soil organisms are not just inhabitants of the soil, they are part of the soil (1), heavily influencing soil properties such as hydrology, aeration and gaseous composition, al1 of which are essential for primary production and the decomposition of organic residues and waste materials.

Whereas soils have been widely studied and classified in terms of physical and chemical characteristics, knowledge of soil biota lags far behind. This is partly due to a lack of recognition of the role of the biota in determining the physical and chemical properties and production potential of soils, and partly due to the bewildering diversity of soil organisms and the resulting taxonomic difficulties faced in identifying the soil's inhabitants. In high input agricultural systems, the importance of soil organisms has often been disregarded, as physical manipulation of the soil, disease and pest suppression, and nutrient supply have been increasingly provided by human inputs rather than by natural processes. However, the current shift towards sustainable land use, in particular sustainable agriculture and forestry, and the growing rec- ognition of the pivotal role of the world's biota as the life-support system for planet Earth, has revived interest in soil biodiversity as an asset to conserve, to understand and to manage wisely in terms of its contribution to ecosystem services.

The objective of this paper is to review the knowledge on the diversity of soil biota and its role in ecosystem functioning, and to identify key areas for future research

Although the diversity of soil organisms is worth conserving and studying in its own right, their functional roles offer a useful framework for making this effort more meaningful. We will first define functional roles in a utilitarian way as ecosystem services. We will then have a closer look at what we mean by biodiversity in soil, emphasizing spheres of influence (2; 'biological systems of regulation' in 3) of the biota in soil and various ways of assembling species in size-classes and functional groups. Subsequently, we relate soil biodiversity to ecosystem processes. Finally, we will address the issue of the knowledge gap and what we need to ascertain in order to relate soil biodiversity to ecosystem functioning and ecosystem services.

\section{ECOSYSTEM SERVICES OF THE SOIL BIOTA}

The soil biota provides a number of ecosystem services that are used by society for its own purposes.

Decomposition of organic matter. When defined simply as mineralization of carbon, $90 \%$ decomposition is carried out by microorganisms such as bacteria and fungi (4). It is greatly facilitated by soil animals such as mites, millipedes, earthworms and termites that shred the residues and disperse microbial propagules. Together they are called decomposers. The soil decomposer community is used for waste management and the purification of polluted soil.

Nutrient cycling is closely associated with organic matter decomposition. Here again, the microorganisms do the job, but the rate at which the processes operate is determined by small grazers such as protozoa and nematodes, while larger animals enhance the process in 'hot spots' such as the gut and excrements. Nutrient cycling by soil biota is essential for all forms of agriculture and forestry. Efficient nutrient cycling on land is also essential for water quality. Specific groups of soil bacteria are involved in autotrophic elemental transformations, i.e. they do not depend on organic matter as a food source.

Bioturbation. Plant roots, ants, termites, earthworms and other soil macrofauna create channels, pores, aggregates and mounds that profoundly influence the transport of gases and water in soil. In so doing they create or modify microhabitats for other, smaller, soil organisms. They are essential for maintaining the structure of soil in agriculture and forestry. Introduction of bioturbators is sometimes used to enhance the decomposition of organic pollutants in soil.

Suppression of soilborne diseases and pests. In natural ecosystems outbreaks of soilborne diseases and pests are relatively rare, whereas they are common in agriculture. It is widely assumed that low plant species diversity renders agroecosystems vulnerable to harmful soil organisms, but the causes of antagonism against pests and diseases in more species-rich systems can be manifold. The potential use of such antagonism in agriculture and forestry is enormous, but the subject is poorly studied.

Soil organisms-and, hence, soils as a whole--are affected 